\title{
How much land can households transfer out to achieve effective poverty reduction? Empirical evidence from China's poverty-stricken areas
}

Jie Cai ( $\nabla$ wh_caijie@126.com )

Chang'an university

Wei Liu

Changan University: Chang'an University

\section{Xianli Xia}

Northwest Agriculture University: Northwest Agriculture and Forestry University

Xiaoping Li

Changan University: Chang'an University

\section{Research Article}

Keywords: households that transfer out land, scale selection, multidimensional poverty reduction, threshold regression model, endogenous switching regression model

Posted Date: March 9th, 2021

DOI: https://doi.org/10.21203/rs.3.rs-306631/v1

License: (9) This work is licensed under a Creative Commons Attribution 4.0 International License. Read Full License 


\begin{abstract}
Land transfer can promote land scale management, realize economies of scale, and improve scale efficiency. Considering the current level of social and economic development, choosing the most appropriate transfer scale can not only increase households' income but also improve their capability. Based on survey data from rural households in China's poverty-stricken areas, this paper uses the threshold regression model to analyze the nonlinear relationship between the land transfer-out scale selection and multidimensional poverty. An endogenous switching regression model, which comprehensively considers the bias and heterogeneity of sample selection, is used to analyze the effect of land transfer on multidimensional poverty. The study yields three main findings. First, the effect of transfer-out rate on the multidimensional poverty index (MPI) structurally changes when the rate reaches 0.7667 . Second, based on counterfactual assumptions, we find that high transfer-out land scale can effectively reduce the MPI. Third, if high transfer-out scale households $(>0.7667)$ choose the low scale, the MPI will increase by 0.0378 ; if low transfer-out scale households $(<0.7667)$ have the opportunity to choose the high scale, the MPI will drop by 0.1297 . Therefore, to achieve better poverty reduction effects in poor areas, policy maker must rationally guide farmers to transfer sufficient land to cross the threshold value for poverty reduction. The government should formulate different guidance strategies for households to transfer out land to improve their capability and avoid falling into multidimensional poverty. Finally, local governments can alleviate multidimensional poverty by increasing support in poor areas and developing the industrial economy.
\end{abstract}

Keywords: households that transfer out land; scale selection; multidimensional poverty reduction; threshold regression model; endogenous switching regression model

\title{
1. Introduction
}

Poverty is a worldwide problem faced by all mankind, and is also the biggest "blocker" to realizing the great rejuvenation of the Chinese nation (Wang et al., 2019). Reducing and eliminating poverty is a long-term task in developing countries (Klasen and Felicitas, 2009; Ravallion, 2016; Wietzke, 2020). The United Nations' Sustainable Development Goals propose that all forms of poverty should be eliminated around the world by 2030, and the Chinese government promised to eliminate absolute poverty by 2020. Since the reform and opening up, China has successfully embarked on a path of poverty alleviation and development with Chinese characteristics, and has made significant contributions to poverty reduction worldwide. Although the absolute number of poor people in China has decreased significantly, 5.51 million people were still in poverty in rural 
areas at the end of 2019. The vast majority of poor people are currently distributed in concentrated, contiguous areas with fragile ecological environments, backward infrastructure, and poor living conditions. In the process of labor non-agriculturalization, farmers in poor areas have not received effective population migration and land transfer, which has formed a special man-land relationship. Land transfer has many potential benefits such as reducing the size of cultivated land, improving the scale of management, promoting non-agricultural employment, ensuring national food security, and improving the flow of households (Li and Zhai, 2018; Tian and He, 2015; Tian and Li, 2014; Xu et al., 2020; Zeng, 2015). In the context of building a well-off society, it is essential to understand how to effectively implement the macro-level design of national land system reform and optimize the market-based allocation of land resources based on micro-level decisions by farmers, in order to achieve the reduction and ultimate eradication of poverty among farmers.

Separation of ownership, contracting rights, management rights, and poverty alleviation are major strategic issues in the process of building a well-off society in an all-round way. Land transfer closely integrates large-scale management of land and anti-poverty work, and is a good channel for systematic poverty alleviation. In recent years, driven by a series of policy documents, land transfer and scale management in rural China have received unprecedented attention. The China's Third Plenary Session of the Eighteenth Central Committee in 2013 proposed the strategic plan of "accelerating the construction of a new agricultural management system." The government aims to achieve the dual goals of increasing grain output and farmers' income by reforming the small-scale farmland management model, as well as realizing the simultaneous development of industrialization, urbanization, and agricultural modernization. China's 2017 Central Rural Work Conference clearly articulated the necessity of combining scale promotion with poverty alleviation and driving farmers to increase their income. Prior studies mainly examine the poverty-reduction effect of land transfer from two aspects. One is the impact of land transfer on income. Some scholars contend that land transfer can increase household income and reduce poverty (Jin and Jayne, 2013; Qian and Wang, 2016; Thuzar, 2010; Zhu et al., 2016). The opposite view is that the instability of transfer rents makes it difficult for households to obtain stable value-added income from farmland (Liu and Zhang, 2014), and land transfer may not necessarily increase households' income (Li and Zhong, 2006; Peng and $\mathrm{Wu}, 2009)$. The other aspect is the impact of land transfer-out on farmers' viability. Some scholars contend that land transfer-out has a significant poverty-alleviation effect in terms of employment and education. However, after transferring out, households may have the short-term behavior of overdrawing physical strength in exchange for income (Cai et al., 2019; Xia and Kuang, 2017; Yuan, 2009). It is difficult to establish a special, high-coverage social security system that assures a certain level of income for transfer-ou households. 
Most of the literature studies the poverty-reduction effect of land transfer from the perspective of income and viability. However, more in-depth research is needed on the nature of the relationship between land transfer and poverty reduction. According to utility maximization theory, there is a complex mechanism between the land transfer-out scale selection and the multidimensional poverty index (MPI). Specifically, the relationship between the transfer-out scale and the MPI may be different either side of a certain threshold for the transfer-out scale. It is, therefore, necessary to verify whether there is a threshold effect in the impact of the land transfer-out scale selection on the MPI. Focused on the actual situation of rural households in the concentrated, contiguous poverty-stricken areas of Liupanshan in China, this paper analyzes the mechanism between land transfer and poverty reduction and seeks to ascertain the threshold value of the transfer-out scale. Its findings should provide insights for promoting efficient land transfer in poor areas and accelerating the fight against poverty.

\section{Data collection and description}

\subsection{Data collection}

The cross-sectional data used in this paper were obtained from a household survey in the concentrated, contiguous, poverty-stricken areas of Liupanshan. The respondents mainly lived in Pengyang County and Yuanzhou District of Ningxia Province; Longxi County, Gangu County, and Maiji District of Gansu Province; and Yongshou County and Chunhua County of Shaanxi Province. The county-level samples were selected using a probability proportional to scale method to ensure representativeness. The specific method for sampling households is as follows: first, select 2-5 townships in the sample county according to the economic development status of townships or towns; second, select 3-5 administrative villages in each sampling township or town; third, randomly select 10-20 households in each administrative village. The research team conducted a large-scale field investigation from November 2015 to May 2016. To improve data reliability, we conducted face-to-face interviews with household heads or other persons in charge. We interviewed a total of 1,260 households. After checking the logic and intervals of the data, we removed questionnaires with missing values. The final sample comprised 572 surveyed households that had transferred out land.

\subsection{Definitions and descriptions of the model variables}

\subsubsection{Dependent variables}

The selection of index weights is a critical issue in measuring poverty. In the absence of uniformity, most multidimensional poverty studies assign an equal weight to each indicator. To avoid the subjective factors on the weighting, this paper uses the equally-weighted method. Drawing on the 
existing literature, we select a comprehensive set of indicators under five dimensions: economy, education, health, living standard, and subjective perception (Alkire and Foster, 2011; Ayuya et al., 2015; Cai et al., 2018; Guo and Qiang, 2016; Mitra et al., 2011; Santos, 2014; Wang and Alkire, 2009; Whelan et al., 2014; Zhang and Zhou, 2014; Zhang et al., 2016; Zhang et al., 2017; Zhu and Li, 2017). The formula for calculating the households' MPI is as follows:

\begin{tabular}{llll} 
Dimension & Indicator & Deprivation threshold & Weight \\
\hline
\end{tabular}

$$
H M P I_{i}=\sum_{j=1}^{d} \omega_{j} y_{i j}
$$

where $\omega_{j}$ represents the weight of the multidimensional poverty indicator, while $y_{i j}$ indicates the value of the $i$-th household on the $j$-th indicator, $i=1,2, \ldots, n ; j=1,2, \ldots, d$.

\section{Table 1}

Multidimensional poverty index: indicators and weights. 


\begin{tabular}{|c|c|c|c|}
\hline Economy & $\begin{array}{l}\text { Per capita } \\
\text { net income }\end{array}$ & $\begin{array}{l}1 \text { if per capita net income is less than RMB 2300a (at } \\
\qquad 2010 \text { constant price); } 0 \text { otherwise }\end{array}$ & $1 / 5$ \\
\hline \multirow[t]{2}{*}{ Education } & $\begin{array}{c}\text { Education } \\
\text { years }\end{array}$ & $\begin{array}{l}1 \text { if the working age population's (16-65 years old) per } \\
\text { capita years of schooling is } 6 \text { years and below (primar } \\
y \text { school); } 0 \text { otherwise }\end{array}$ & $1 / 10$ \\
\hline & $\begin{array}{l}\text { Education } \\
\text { expenditure }\end{array}$ & $\begin{array}{l}1 \text { if the family's education expenditure burden is higher } \\
\text { than } 50 \% ; 0 \text { otherwise }\end{array}$ & $1 / 10$ \\
\hline \multirow[t]{3}{*}{ Health } & $\begin{array}{l}\text { Health stat } \\
\text { us }\end{array}$ & $\begin{array}{c}1 \text { if there are persons with disabilities or major illnesses } \\
\text { in the family; } 0 \text { otherwise }\end{array}$ & $1 / 15$ \\
\hline & $\begin{array}{l}\text { Medical ex } \\
\text { penditure }\end{array}$ & $\begin{array}{l}1 \text { if family medical expenditure accounts for } 50 \% \text { of tot } \\
\text { al household expenditure and above; } 0 \text { otherwise }\end{array}$ & $1 / 15$ \\
\hline & $\begin{array}{l}\text { Timely assi } \\
\text { stance }\end{array}$ & $\begin{array}{l}1 \text { if family members are sick and cannot get help prom } \\
\text { ptly; } 0 \text { otherwise }\end{array}$ & $1 / 15$ \\
\hline \multirow[t]{3}{*}{$\begin{array}{l}\text { Living stan } \\
\text { dard }\end{array}$} & $\begin{array}{l}\text { Clean drink } \\
\text { ing water }\end{array}$ & $\begin{array}{l}1 \text { if no tap water or deep well water }(\geq 5 \mathrm{~m}) \text { in the hom } \\
\qquad \text { e; } 0 \text { otherwise }\end{array}$ & $1 / 15$ \\
\hline & $\begin{array}{l}\text { Sanitary fa } \\
\text { cilities }\end{array}$ & 1 if there is no indoor toilet; 0 otherwise & $1 / 15$ \\
\hline & Housing & 1 if housing structure is the civil structure; 0 otherwise & $1 / 15$ \\
\hline $\begin{array}{l}\text { Subjective } \\
\text { perception }\end{array}$ & $\begin{array}{l}\text { Perception } \\
\text { of life satis } \\
\text { faction }\end{array}$ & $\begin{array}{c}1 \text { if the household is dissatisfied with current life; } 0 \text { oth } \\
\text { erwise }\end{array}$ & $1 / 5$ \\
\hline
\end{tabular}

Notes: ${ }^{\text {a }}$ during the survey period; ${ }^{\mathrm{b}}$ USD 1 was approximately equal to RMB 6.23.

\subsubsection{Independent variables}

The basic principle of the endogenous conversion model is to select identification variables that affect land transfer-out scale selection but not multidimensional poverty. Agricultural production capacity and negotiation time both meet these criteria and so were selected as identification variables. Table 2 presents all the variables used in this paper, many of which were chosen based on the results of Shi et al. (2017). As Table 2 shows, the average value of MPI of the households that had transferred out land in the Liupanshan area is $16.17 \%$, while the average transfer-out rate is $54.92 \%$. The average age of the household head is 53.1 years, while the average total education of the household head is only 7 years. The agricultural production capacity of transfer-out households is low (the proportion of agricultural income to total household income is $17.68 \%$ ), and the average agricultural land area is $11.4777 \mathrm{mu}$. 


\section{Table 2}

Variable meanings and descriptive statistics.

\begin{tabular}{|c|c|c|c|}
\hline Variable names & Calculation & Mean & $\mathrm{SD}$ \\
\hline $\begin{array}{c}\text { Multidimensional } \\
\text { poverty index }\end{array}$ & $\begin{array}{c}0.2 * \text { economic dimension }+0.2 * \text { education } \\
\text { dimension }+0.2 * \text { health dimension }+0.2 * \text { living } \\
\text { standards dimension }+0.2 * \text { subjective perception }\end{array}$ & 0.1617 & 0.1416 \\
\hline Transfer-out scale & $\begin{array}{l}\text { Farmland transfer-out rate }=\text { transferred-out area } \\
\text { between } 2010 \text { and } 2015 \text { / shared farmland area. } \\
\text { Shared farmland area }=\text { actual operating area of } \\
\text { households in } 2010 .\end{array}$ & 0.5492 & 0.2865 \\
\hline Age of household head & Actual age of household head (years) & 53.0701 & 11.0539 \\
\hline $\begin{array}{c}\text { Education years of } \\
\text { household head }\end{array}$ & Actual years of education of household head (years) & 6.9546 & 3.7069 \\
\hline Family structure & $\begin{array}{c}\text { Using average age of adults: } \\
1=\text { young families }(\leq 29 \text { years old }) ; \\
2=\text { young } \& \text { middle-aged families }(30-39 \mathrm{y} / \mathrm{o}) ; \\
3=\text { middle-aged families }(40-49 \mathrm{y} / \mathrm{o}) ; \\
4=\text { middle-aged } \& \text { elderly families }(50-59 \mathrm{y} / \mathrm{o}) ; \\
5=\text { old family }(\geq 60 \mathrm{y} / \mathrm{o})\end{array}$ & 3.0308 & 0.9735 \\
\hline $\begin{array}{l}\text { Education years of } \\
\text { adults }\end{array}$ & Average years of education of adults & 7.2827 & 2.8741 \\
\hline House value & $\begin{array}{l}\text { Converted into present value (RMB, logarithm) } \\
\text { based on the structure, cost of construction, and } \\
\text { service life of the farmer's house }\end{array}$ & 11.1763 & 1.1886 \\
\hline $\begin{array}{l}\text { Agricultural machinery } \\
\text { value }\end{array}$ & Converted into present value (RMB, logarithm) & 3.1368 & 4.0952 \\
\hline Agricultural land area & $\begin{array}{l}\text { Agricultural land area shared by households (based } \\
\qquad \text { on } 2010, \mathrm{mu}^{\mathrm{a}} \text { ) }\end{array}$ & 11.4777 & 8.5864 \\
\hline New Year's scale & $\begin{array}{c}\text { Relatives and friends (households) visited during the } \\
\text { New Year, this is used to measure the social capital } \\
\text { of households }\end{array}$ & 13.4342 & 7.9130 \\
\hline $\begin{array}{l}\text { Village economic } \\
\text { development level }\end{array}$ & Per capita income of villagers (RMB, logarithm) & 8.5949 & 0.3466 \\
\hline
\end{tabular}




\begin{tabular}{|c|c|c|c|}
\hline $\begin{array}{l}\text { Village transportation } \\
\text { convenience }\end{array}$ & $\begin{array}{l}\text { Actual distance of the village from the county center } \\
\qquad \text { (miles, logarithm) }\end{array}$ & 3.4273 & 0.5880 \\
\hline Regional & $1=$ Yes $; 0=\mathrm{No}$ & 0.3231 & 0.4681 \\
\hline \multicolumn{4}{|l|}{ characteristics - whether } \\
\hline \multicolumn{4}{|l|}{ located in Ningxia } \\
\hline Regional & $1=$ Yes $; 0=$ No & 0.3692 & 0.4830 \\
\hline \multicolumn{4}{|l|}{ characteristics - whether } \\
\hline \multicolumn{4}{|l|}{ located in Gansu } \\
\hline $\begin{array}{l}\text { Agricultural production } \\
\text { capacity }\end{array}$ & $\begin{array}{l}\text { Proportion of agricultural income to total household } \\
\text { income }(\%)\end{array}$ & 17.6805 & 23.4261 \\
\hline Negotiation time & $\begin{array}{l}\text { Time spent on land transfer price negotiation: } 1=\text { No } \\
\text { time spent; } 2=\text { Short time; } 3=\text { Long time }\end{array}$ & 1.2803 & 0.5235 \\
\hline
\end{tabular}

Note: ${ }^{a} 1 \mathrm{mu}$ is approximately equal to $667 \mathrm{~m}^{2}$ or 0.067 ha.

\section{Econometric model}

\subsection{Threshold regression model}

In this paper, the threshold regression model is established with the transfer-out scale as the threshold variable. Established by Hansen (2000), the threshold regression model can be used for both cross-sectional data and panel data estimation. We construct the following basic model:

$$
\begin{aligned}
& y_{i}=\theta_{1}^{\prime} x_{i}+\varepsilon_{i}, \quad q_{i} \leq \gamma \\
& y_{i}=\theta_{2}^{\prime} x_{i}+\varepsilon_{i}, \quad q_{i}>\gamma
\end{aligned}
$$

where $y_{i}$ represents the dependent variable; $x_{i}$ represents the independent variable; $q_{i}$ represents the threshold variable; and $\gamma$ represents the threshold value. $q_{i}$ can be divided into two regimes according to $\gamma \cdot \theta_{1}^{\prime}$ and $\theta_{2}^{\prime}$ represent the respective regression coefficients of the two regime samples. $\varepsilon_{i}$ represents the random error term, $\varepsilon_{i} \sim \operatorname{iid}\left(0, \sigma^{2}\right)$.

To simplify the model, we define the dummy variable $d_{i}(\gamma)=\left\{q_{i} \leq \gamma\right\}$, where $\{\cdot\}$ represents the indicator function. We also set $x_{i}(\gamma)=x_{i} d_{i}(\gamma)$. Eq. (2) and Eq. (3) can thus be combined in the following single equation:

$$
y_{i}=\theta^{\prime} x_{i}+\delta_{n}^{\prime} x_{i}(\gamma)+\varepsilon_{i}
$$


where $\theta=\theta_{2}, \delta_{n}=\theta_{2}-\theta_{1}$. We use the following matrix form to express the model:

$$
y=X \theta+X_{\gamma} \delta_{n}+\varepsilon
$$

where $\left(\theta, \delta_{n}, \gamma\right)$ are the regression parameters. According to the least squares estimation method, the sum of squared residuals of the model can be expressed as:

$$
S_{n}(\theta, \delta, \gamma)=\left(Y-X \theta-X_{\gamma} \delta\right)^{\prime}\left(Y-X \theta-X_{\gamma} \delta\right)
$$

To make Eq. (6) satisfy the least square estimation method, we define the statistics $\hat{\theta}, \hat{\delta}$, and $\hat{\gamma}$. To minimize the $S_{n}$, we set $\gamma$ as a restricted variable and satisfy $[\underline{\gamma}, \bar{\gamma}]=\Gamma$. We use maximum likelihood estimation, with the random error $\varepsilon_{i} \sim \operatorname{iid}\left(0, \sigma^{2}\right)$.

In Eq. (6), $\theta$ and $\delta_{n}$ are linearly related, then we use ordinary least squares regression. We also use $X_{\gamma}^{*}=\left[X X_{\gamma}\right]$ to return to $Y$, and obtain $\hat{\theta}(\gamma)$ and $\hat{\delta}(\gamma)$. The corresponding sum of squared residual functions can be expressed as $S_{n}(\gamma)=S_{n}(\hat{\theta}(\gamma), \hat{\delta}(\gamma), \gamma)=Y^{\prime} Y-Y^{\prime} X_{\gamma}^{*}\left(X_{\gamma}^{*^{\prime}} X_{\gamma}^{*}\right)^{-1} X_{\gamma}^{*} Y$. It can be deduced that what makes $S_{n}(\gamma)$ satisfy the minimum value $\gamma$ is the estimated threshold value, defined as $\hat{\gamma}=\arg \min _{\gamma=\Gamma_{n}} S_{n}(\gamma)$.

For the estimated threshold, we need to further verify whether there is a significant difference between the estimated coefficients of the two regime samples above and below the threshold. We set the null hypothesis as $\mathrm{H}_{0}: \theta_{1}=\theta_{2}$, and the alternative hypothesis as $\mathrm{H}_{1}: \theta_{1} \neq \theta_{2}$. Under the null hypothesis assumption, the threshold value $\gamma$ is difficult to identify. We use the algorithm proposed by Hansen (2000) to obtain the progressive distribution and use the bootstrap method to obtain the corresponding $p$-value (the bootstrap $p$-value).

Under the premise that the threshold variable has a threshold effect, we need to further test the confidence interval of the threshold, and thus verify whether the null hypothesis $\mathrm{H}_{0}: \gamma=\hat{\gamma}$ is true. The likelihood ratio statistics can be expressed as:

$$
L R_{n}=n \frac{S_{n}-S_{n}(\hat{\gamma})}{S_{n}(\hat{\gamma})}
$$

Considering that the likelihood ratio statistics are also non-standard (Hansen, 2000), the null hypothesis should satisfy $L R_{n}(\gamma) \leq c(\alpha)=-2 \ln (1-\sqrt{z})$. 


\subsection{Endogenous switching regression model}

Households self-select in land transfer-out scale selection, and there is large heterogeneity in transfer-out scale between households. Accordingly, this paper uses an endogenous switching regression (ESR) model to estimate the impact of land transfer-out scale selection on multidimensional poverty. The basic idea of the ESR model is to estimate the impact of farmers' transfer-out on multidimensional poverty by:

(1) using a logit or probit model to estimate the selection equation of households' transfer-out scale (assuming high transfer-out scale is 1 and low transfer-out scale is 0 ); and

(2) constructing a multidimensional poverty model for households, and estimating the effect of transfer-out scale selection on multidimensional poverty.

As rational actors, households should only choose high transfer-out scale when the potential return is higher than that for low transfer-out scale. The equation for households' transfer-out scale selection can be expressed as:

$$
\begin{aligned}
& T_{i}^{*}=Z_{i}^{\prime} \gamma+\mu_{i} \\
& T_{i}=\left\{\begin{array}{l}
1, T_{i}^{*}>0 \\
0, T_{i}^{*} \leq 0
\end{array}\right.
\end{aligned}
$$

The multidimensional poverty models for households with high transfer-out scale and households with low transfer-out scale are expressed as:

$$
\begin{aligned}
& Y_{i t}=X_{i t}^{\prime} \beta_{t}+\varepsilon_{i t} \\
& Y_{i u}=X_{i u}^{\prime} \beta_{u}+\varepsilon_{i u}
\end{aligned}
$$

where $T_{i}^{*}$ is a latent variable indicating whether the household "chooses" a high transfer-out scale.

This variable cannot be observed but is expressed by a series of observable exogenous variables. $Y_{i t}$

and $Y_{i u}$ represent the multidimensional poverty situation of households with high transfer-out scale and low transfer-out scale, respectively. $Z$ represents a set of explanatory variables that affect households' transfer-out scale selection, and $X$ represents a set of explanatory variables that affect the multidimensional poverty of households . $\mu_{i}, \varepsilon_{i t}$, and $\varepsilon_{i u}$ represent random disturbance. In addition, to ensure the endogenous conversion model can run effectivelyl, one variable must be included in vector $Z$ that is not included in vector $X$.

To avoid the problem of sample selection bias caused by unobservable factors, the inverse Mills ratios $\lambda_{i t}$ and $\lambda_{i u}$, calculated in the transfer-out scale selection model, were introduced into the 
multidimensional poverty model. The maximum likelihood value of complete information is used to estimate households' transfer-out scale selection and multidimensional poverty. For this purpose, Eq. (9-1) and (9-2) are expressed as:

$$
\begin{gathered}
Y_{i t}=X_{i t}^{\prime} \beta_{t}+\sigma_{\mu t} \lambda_{i t}+\varepsilon_{i t} \\
Y_{i u}=X_{i u}^{\prime} \beta_{u}+\sigma_{\mu u} \lambda_{i u}+\varepsilon_{i u}
\end{gathered}
$$

wherev $\lambda_{i t}$ and $\lambda_{i u}$ represent the deviation of transfer-out scale selection caused by factors such as the unobserved ability or preference of the household; $\sigma_{\mu t}$ and $\sigma_{\mu u}$ represent the error terms of the transfer-out scale selection equation variance and multidimensional poverty equation variance, respectively: $\sigma_{\mu t}=\operatorname{cov}\left(\varepsilon_{i t}, \mu_{i}\right), \sigma_{\mu u}=\operatorname{cov}\left(\varepsilon_{i u}, \mu_{i}\right)$.

\subsection{Evaluation of treatment effect based on the ESR model}

Based on the ESR model, the MPI values of households with high transfer-out scale and low transfer-out scale are respectively expressed as follows:

$$
\begin{gathered}
E\left[Y_{i t} \mid T_{i}=1\right]=X_{i t}^{\prime} \beta_{t}+\sigma_{\mu t} \lambda_{i t} \\
E\left[Y_{i u} \mid T_{i}=0\right]=X_{i u}^{\prime} \beta_{u}+\sigma_{\mu u} \lambda_{i u}
\end{gathered}
$$

Consider the following two counterfactual hypotheses: (1) households with high transfer-out scale have the chance to choose the low transfer-out scale; and (2) households with low transfer-out scale have the chance to choose the high transfer-out scale. The conditional expectations can be expressed as:

$$
\begin{gathered}
E\left[Y_{i u} \mid T_{i}=1\right]=X_{i t}^{\prime} \beta_{u}+\sigma_{\mu u} \lambda_{i t} \\
E\left[Y_{i t} \mid T_{i}=0\right]=X_{i u}^{\prime} \beta_{t}+\sigma_{\mu t} \lambda_{i u}
\end{gathered}
$$

The average treatment effect on the MPI of rural households with high transfer-out scale can be expressed as the difference between Eq.(11-1) and Eq. (12-1):

$$
A T T=E\left[Y_{i t} \mid T_{i}=1\right]-E\left[Y_{i u} \mid T_{i}=1\right]=X_{i t}^{\prime}\left(\beta_{t}-\beta_{u}\right)+\lambda_{i t}\left(\sigma_{\mu t}-\sigma_{\mu u}\right)
$$

Similarly, the average treatment effect on the MPI of rural households with low transfer-out scale can be expressed as the difference between Eq. (11-2) and Eq. (12-2):

$$
A T U=E\left[Y_{i t} \mid T_{i}=0\right]-E\left[Y_{i u} \mid T_{i}=0\right]=X_{i u}^{\prime}\left(\beta_{t}-\beta_{u}\right)+\lambda_{i u}\left(\sigma_{\mu t}-\sigma_{\mu u}\right)
$$

\section{Results}

\subsection{Threshold effect of households' transfer-out scale selection}

According to the basic principle of the threshold regression model, the threshold variable can either be exogenous or explanatory. When there is a nonlinear relationship between the explanatory 
variable and the explained variable, the threshold regression model can better fit the regression results (Liu et al., 2014). In this paper, households' transfer-out scale is used as a threshold variable to test whether there is a nonlinear relationship between the transfer-out scale and multidimensional poverty of households in China's Liupanshan area. In other words, it is used to verify whether there is a critical value for the transfer-out scale. As different households have different farmland endowments and different agricultural land areas, using the transfer-out area to represent the transfer-out scale will produce a large error. Therefore, we use the transfer-out rate to represent transfer-out scale.

According to the threshold model constructed above, to select the optimal threshold variable, we must first conduct a threshold effect test. We use the test method of Hansen (2000) to construct LR statistics and use bootstrapping to obtain the corresponding $p$-value (Yang and Li, 2016).

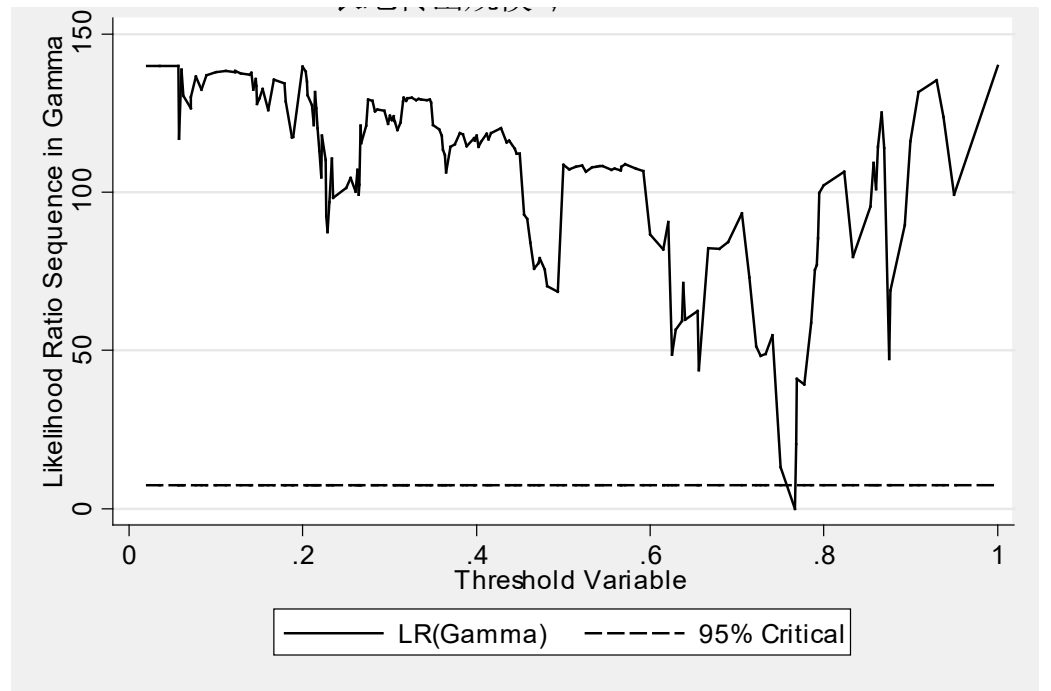

Fig. 1. The first round: threshold variable Transfer-out scale.

In the first round of threshold regression, the LR value and bootstrap $p$-value are 11.2470 and 0.0406 , respectively, which indicates that the model rejects the null hypothesis at the $5 \%$ significance level. In other words, the transfer-out scale is likely to have a threshold effect on the multidimensional poverty of households that transfer out land. The heteroskedasticity test $p$-value is 0.0285 , so the null hypothesis of the same variance assumption cannot be rejected, which means that the model does not have heteroscedasticity. Fig. 1 shows the trend graph of the LR. We find that the threshold of transfer-out scale is 0.7667 , which is the lowest point in Fig. 1. At a 95\% confidence level, all of the 585 respondents fell outside the confidence interval [0.7667, 0.7667]. That is, at the threshold of 0.7667 , the relationship between the transfer-out scale and the MPI changed significantly. Therefore, we can divide the households into low transfer-out scale $(\leq 76.67 \%)$ and 
high transfer-out scale $(>76.67 \%)$.

We next conducted a second round of threshold regression separating the 152 households with low transfer-out scale and the 433 households with high transfer-out scale. For the low transfer-out scale group, the LR value and bootstrap $p$-value are 4.9076 and 0.2576 , respectively. This indicates that the model rejects the null hypothesis for these households: that is, the transfer-out scale is not a threshold variable that affects households' multidimensional poverty. For the high transfer-out scale group, the LR value and bootstrap $p$-value are 4.8311 and 0.5408 , respectively, which indicates that the model also rejects the null hypothesis for these households (i.e., transfer-out scale is not a threshold variable that affects households' multidimensional poverty). As the results of the second round of testing are not significant, there is no need to further divide the sub-samples. There is evidently a nonlinear relationship between the transfer-out scale and multidimensional poverty, and the threshold test results reveal a structural mutation in the relationship at the land transfer-out rate of 0.7667 .

\subsection{The impact of transfer-out scale selection on multidimensional poverty}

\subsubsection{Analysis of the ESR model estimation results}

The results of the joint estimation of transfer-out scale selection and multidimensional poverty are shown in Table 3. The fourth column reports the estimation results for factors affecting transfer-out scale selection, while the second and the third columns report the estimation results for factors influencing multidimensional poverty for households with high transfer-out scale and households with low transfer-out scale, respectively. The correlation coefficient $\rho_{\mu t}^{1}$ between the error term of the transfer-out scale selection and multidimensional poverty of high transfer-out households is 0.8802 . The correlation coefficient $\rho_{\mu n}^{1}$ between the error term of the transfer-out scale selection and multidimensional poverty of high transfer-out households is 0.1329 . Both $\rho_{\mu t}^{1}$ and $\rho_{\mu n}^{1}$ are significant at the $10 \%$ level, which indicates that there is sample selection bias in the multidimensional poverty model. $\rho_{\mu t}^{1}>\rho_{\mu n}^{1}$ shows that the necessary conditions for consistency are satisfied (Abdulai and Huffman, 2014). The MPI of households with high transfer-out scale is higher than that of households with low transfer-out scale .

\section{Table 3}

Results of joint estimation of households' transfer-out scale and multidimensional poverty index.

Variable

Multidimensional poverty equation

Transfer-out

Households with Households with

scale selection 


\begin{tabular}{|c|c|c|c|}
\hline & $\begin{array}{c}\text { high transfer-out } \\
\text { scale }\end{array}$ & $\begin{array}{c}\text { low transfer-out } \\
\text { scale }\end{array}$ & equation \\
\hline \multirow[t]{2}{*}{ Age of household head } & 0.0054 & -0.0006 & -0.0001 \\
\hline & $(0.0015)$ & $(0.0007)$ & $(0.0079)$ \\
\hline \multirow[t]{2}{*}{ Education years of household head } & 0.0025 & -0.0009 & 0.0018 \\
\hline & $(0.0048)$ & $(0.0023)$ & $(0.0249)$ \\
\hline \multirow[t]{2}{*}{ Family structure } & 0.0034 & 0.0086 & 0.1217 \\
\hline & $(0.0174)$ & $(0.0090)$ & $(0.0922)$ \\
\hline \multirow[t]{2}{*}{ Education years of adults } & $-0.0233^{* * *}$ & $-0.0102^{* * *}$ & -0.0168 \\
\hline & $(0.0065)$ & $(0.0032)$ & $(0.0344)$ \\
\hline \multirow[t]{2}{*}{ House value } & $-0.0287^{* * *}$ & $-0.0267^{* * *}$ & -0.0846 \\
\hline & $(0.0102)$ & $(0.0054)$ & $(0.0579)$ \\
\hline \multirow[t]{2}{*}{ Agricultural machinery value } & $-0.0069^{*}$ & 0.0002 & $-00382^{* *}$ \\
\hline & $(0.0036)$ & $(0.0017)$ & -0.0502 \\
\hline \multirow[t]{2}{*}{ Agricultural land area } & -0.0000 & $-0.0024^{* *}$ & -0.0108 \\
\hline & $(0.0016)$ & $(0.0009)$ & $(0.0092)$ \\
\hline \multirow[t]{2}{*}{ New Year's scale } & -0.0005 & -0.0004 & 0.0134 \\
\hline & $(0.0016)$ & $(0.0009)$ & $(0.0086)$ \\
\hline \multirow[t]{2}{*}{ Village economic development level } & -0.0199 & -0.0242 & 0.2771 \\
\hline & $(0.0338)$ & $(0.0201)$ & $(0.1966)$ \\
\hline \multirow[t]{2}{*}{ Village transportation convenience } & -0.0180 & $0.0324^{* * *}$ & $-0.2136^{*}$ \\
\hline & $(0.0250)$ & $(0.0126)$ & $(0.1174)$ \\
\hline Regional characteristics-whether & $0.0778^{* *}$ & 0.0300 & $0.6873^{* * *}$ \\
\hline located in Ningxia & $(0.0338)$ & $(0.0188)$ & $(0.1592)$ \\
\hline Regional characteristics-whether & -0.0150 & -0.0057 & $-0.4100^{* *}$ \\
\hline located in Gansu & $(0.0411)$ & $(0.0180)$ & $(0.1907)$ \\
\hline \multirow[t]{2}{*}{ Agricultural production capacity } & -- & -- & $-0.0232^{* * *}$ \\
\hline & & - & $(0.0045)$ \\
\hline \multirow[t]{2}{*}{ Negotiation time } & & & $-0.1931^{*}$ \\
\hline & -- & -- & $(0.1215)$ \\
\hline \multirow[t]{2}{*}{ Constants } & $0.6958^{* *}$ & $0.6782^{* * *}$ & -1.1218 \\
\hline & $(0.3478)$ & $(0.1992)$ & $(2.0168)$ \\
\hline \multirow{2}{*}{$\operatorname{Ln} \sigma_{\mu t}^{1}$} & $-1.9067^{* * *}$ & & \\
\hline & $(0.1628)$ & -- & -- \\
\hline \multirow{2}{*}{$\rho_{\mu t}^{1}$} & $0.8802^{*}$ & & \\
\hline & $(0.4767)$ & -- & -- \\
\hline $\operatorname{Ln} \sigma_{\mu n}^{1}$ & -- & $\begin{array}{c}-2.0806^{* * *} \\
(0.0357) \\
\end{array}$ & -- \\
\hline
\end{tabular}




\begin{tabular}{|c|c|c|c|}
\hline$\rho_{\mu n}^{1}$ & -- & $\begin{array}{c}0.1329^{*} \\
(0.2262)\end{array}$ & -- \\
\hline LR & & $5.86^{* *}$ & \\
\hline log likelihood & & 22.3278 & \\
\hline Sample size & 152 & 433 & 585 \\
\hline
\end{tabular}

Notes: $*, * *$, and $* * *$ indicate significance at the $10 \%, 5 \%$, and $1 \%$ level, respectively. Standard errors in parentheses.

\subsubsection{Analysis of regression results for transfer-out scale selection}

Agricultural machinery value has a negative impact on the scale selection of households that transfer out land, significant at the 5\% significance level. This means that the higher the agricultural machinery value, the greater the likelihood of households choosing the low transfer-out scale. Households with high agricultural machinery value mostly live on agriculture, and their agricultural production has a relatively high degree of mechanization. Consequently, transferring out has a higher opportunity cost for these households, so they tend to transfer out less land. Our finding is thus consistent with the actual situation. Village transportation convenience also negatively impacts on the transfer-out scale selection, significant at the $10 \%$ level. This means that the greater the distance between the village and the county center, the greater the likelihood of households choosing the high transfer-out scale. This may be due to the rapid development of industrialization and the acceleration of urbanization, non-agricultural employment in cities has created a strong attraction for farmers who transfer from farmland. Considering the higher opportunity cost of agricultural production, households located further away from the county center are inclined to transfer out more land in order to reduce the constraints of agricultural production on labor. Whether households are located in Ningxia positively impacts transfer-out scale selection at the $10 \%$ significance level. This means that, compared with transfer-out households in Gansu and Shaanxi, the transfer-out households in Ningxia are more inclined to choose the high transfer-out scale. Relatedly, whether households are located in Gansu negatively impacts on transfer-out scale selection at the 5\% significance level: compared with transfer-out households in Ningxia and Shaanxi, the transfer-out households in Gansu are more inclined to choose the low transfer-out scale.

Turning next to the identification variables, agricultural production capacity negatively impacts on transfer-out scale selection at the $1 \%$ significance level. This means that as agricultural production capacity improves, households are more inclined to choose the low transfer-out scale. This may be explained by most households with high agricultural productivity living on agriculture, with agricultural income contributing a large proportion of total household income. Moreover, given the instability of non-agricultural income, the guaranteed income of agricultural land is especially valued. 
Households with agricultural income hope to maintain the sustainable development of their families through agricultural production, and so their transfer-out scale is relatively small. Negotiation time negatively impacts on transfer-out scale selection at the $10 \%$ significance level: as negotiation time increases, households are more inclined to choose the low transfer-out scale. This may be due to the time-consuming negotiation in the process of land transfer, which has increased the negotiation cost of the transfer-out households and reduced the expected income of the transfer-out household. Therefore, the households with higher negotiation costs usually choose the low transfer-out scale.

\subsubsection{Analysis of regression results for the multidimensional poverty of transfer-out households}

Education years of adults and house value both affect the multidimensional poverty of transfer-out households. Education years of adults negatively impacts on the MPI of transfer-out households at the $1 \%$ significance level. This means that as the number of education years increases, the MPI shows a downward trend. House value also negatively impacts on the MPI of transfer-out households at the $1 \%$ significance level: as house value rises, the MPI shows a downward trend. This is mainly because the general living conditions of high-value households are relatively good, and their overall requirements for life are high. They can meet their living standards by increasing agricultural income or non-agricultural income. On this basis, those households continuously improve their viability, thereby reducing the MPI. For households with high transfer-out scale, those with high house value continuously improve their social adaptability to maintain or improve their current living standards. They also increase the overall income level of their families through non-agricultural employment, thus reducing the MPI.

Both agricultural machinery value and whether located in Ningxia affect the MPI of households with high transfer-out scale. As the agricultural machinery value increases, the MPI of households with high transfer-out scale shows a downward trend, significant at the $10 \%$ level. By contrast, being located in Ningxia has a positive impact on the MPI of households with high transfer-out scale, significant at the 5\% level. This means that, compared with households in Gansu and Shaanxi with high transfer-out scale, high transfer-out households in Ningxia have a higher MPI.

Agricultural land area and village transportation convenience both affect the MPI of households with low transfer-out scale. As the agricultural land area increases, the MPI of households with low transfer-out scale shows a decreasing trend, significant at the 5\% level. By contrast, village transportation convenience positively impacts on the MPI of low transfer-out households, significant at the $1 \%$ level. In other words, as the distance from village to the county center increases, the MPI of households with low transfer-out scale shows an upward trend. 


\subsubsection{Analysis of treatment effect}

The treatment effect of the transfer-out scale selection on households' MPI is calculated using Eq. (13) and Eq. (14), and the results are shown in Table 4. Among them, (a) represents the actual MPI of households with high transfer-out scale and (d) represents the actual MPI of households with low transfer-out scale. Both (b) and (c) represent the estimation results under the counterfactual hypothesis.

Table 4 shows the average treatment effect on the MPI of households with high transfer-out scale (ATT) and the average treatment effect on the MPI of households with low transfer-out scale (ATU). Both ATT and ATU are significant test at the 1\% level.

\section{Table 4}

Treatment effect of transfer-out scale selection on the multidimensional poverty index (MPI).

\begin{tabular}{ccccc}
\hline & High transfer-out scale & Low transfer-out scale & ATT & ATU \\
\hline $\begin{array}{c}\text { Households with high } \\
\text { transfer-out scale }\end{array}$ & (a) 0.1626 & (b) 0.2004 & $-0.0378^{* * *}$ & -- \\
$\begin{array}{l}\text { Households with low } \\
\text { transfer-out scale }\end{array}$ & (c) -0.0306 & (d) 0.1613 & -- & $-0.1297^{* * *}$ \\
\hline
\end{tabular}

Notes: ATT: average treatment effect on the MPI of high transfer-out households; ATU: average treatment effect on the MPI of low transfer-out households. $*, * *$, and $* * *$ indicate significance at the $10 \%, 5 \%$, and $1 \%$ level, respectively.

Regarding the estimated results for the counterfactual hypothesis, if a household with high transfer-out scale chooses the low scale, the MPI will increase by 0.0378 (18.86\%); if a household with low transfer-out scale has the opportunity to choose the high scale, the MPI will decrease by 0.1297 (80.41\%). These results indicate that high transfer-out scale can effectively reduce the MPI of households.

The absolute value of ATT is significantly smaller than that of ATU. Although high transfer-out scale selection can reduce the MPI of households, it is constrained by the preference of households in the Liupanshan area to live on the land and their inability to fully combine their own advantages to choose the optimal transfer-out scale.

\subsection{Robustness test}

To test the robustness of the model estimation results, we randomly selected $85 \%$ of respondents to construct a new sample of 497 households that transfer out land, and then repeated the endogenous conversion estimations. Because the estimated coefficients and significance in the new 
sample are basically consistent with those in Table 3, this section only reports the estimation results for the treatment effect of transfer-out scale selection on MPI. As shown by the regression results presented in Table 5, the estimated results for each treatment effect are basically consistent with the estimated results in Table 4, indicating that the endogenous conversion model estimates are robust.

\section{Table 5}

Robustness test results.

\begin{tabular}{lcccc}
\hline & High transfer-out scale & Low transfer-out scale & ATT & ATU \\
\hline $\begin{array}{c}\text { Households with high } \\
\text { transfer-out scale }\end{array}$ & (a) 0.1648 & (b) 0.2229 & -0.0581 & \\
$\begin{array}{c}\text { Households with low } \\
\text { transfer-out scale }\end{array}$ & (c) -0.0526 & (d) 0.1646 & -- \\
\hline
\end{tabular}

Note: ATT: average treatment effect on the MPI of high transfer-out households; ATU: average treatment effect on the MPI of low transfer-out households. *, *,**, and *** indicate significance at the $10 \%, 5 \%$, and $1 \%$ level, respectively.

\section{Conclusion}

This paper empirically analyzed field survey data of 585 households that had transferred out land in China's Liupanshan area. First, we used a threshold regression model to measure the threshold of the effect of transfer-out scale selection on multidimensional poverty. We then divided the sample into households with high transfer-out scale and households with low transfer-out scale. Second, the ESR model was used to analyze factors influencing transfer-out scale selection and factors affecting the multidimensional poverty of households that transfer out land. Finally, we analyzed the average treatment effect of transfer-out households' scale selection on multidimensional poverty. The results revealed a nonlinear relationship between transfer-out scale selection and multidimensional poverty. Specifically, the relationship structurally mutates at the transfer-out rate of 0.7667. On this basis, we divided households according to whether their transfer-out rate was above (high transfer-out scale) or below (low transfer-out scale) the rate of 0.7667 . Our analysis revealed that high transfer-out scale can effectively reduce households' MPI. If households with high transfer-out scale choose the low transfer-out scale, their MPI will increase by 0.0378 ; if households with low transfer-out scale have the opportunity to choose the high scale, their MPI will decrease by 0.1297 .

In recent years, national policies and the combination of three industrial developments have improved the economy and industries in poor areas. However, due to the poor endowment of land 
resources in poor areas, households' agricultural operating income remains low. Some farmers have released some land and labor bound to agriculture by transferring out farmland. This results in a relatively stable turnover rental income and non-agricultural employment income, which has somewhat alleviated multidimensional poverty. To enable households in poor areas to experience greater poverty reduction after transferring out land, these households must fully understand their resource endowment. For this purpose, it is reasonable to guide households on transfer scale required to cross the threshold value for reducing poverty. The government could also encourage households with high transfer-out scale to actively participate in non-agricultural employment, improve their viability, and avoid falling into multidimensional poverty due to deprivation of capacity. Households with low transfer-out scale are encouraged to work nearby to increase their non-agricultural employment income. By the same time, these households should improve their viability and avoid falling into multidimensional poverty. Finally, local governments should continue to support poor areas, introduce and cultivate new types of agricultural business entities, and develop industrial economies: all of these actions can alleviate multidimensional poverty at source.

Author Contributions: J.C. and X.X. designed the research and wrote the paper. L.L., Y.C. and X. W. revised the paper. All authors have read and agreed to the published version of the manuscript.

Funding: This research was funded by the Shaanxi Provincial Social Science Research Project on Major Theoretical and Realistic Problems in 2020 (Grant No. $2020 \mathrm{Z} 355$ and 20FN-205), Shaanxi Provincial Social Science Foundation (Grant Nos. 2020R026 and 2020ZDWT15), and Chang'an University Central University Basic Research Business Expenses Special Fund Project (Grant Nos. 300102119623 and 300102110655 ).

Conflicts of Interest: The authors declare no conflict of interest.

\section{References}

Abdulai, A., Huffman, W. 2014. The adoption and impact of soil and water conservation technology: an endogenous switching regression application. Land Economics 90(1), 26-43.

Alkire, S., Foster, J. 2011. Counting and multidimensional poverty measurement. Journal of Public Economics 95(7-8), 476-487.

Ayuya, O.I., Gido, E.O., Bett, H.K., Lagat, J.K., Kahi, A.K., Bauer, S.. 2015. Effect of certified organic production systems on poverty among smallholder farmers: empirical evidence from Kenya. World Development 67, 27-37.

Cai, J., Xia, X.L., Wang, T. 2018. The influence of land renting-out incentive of peasant households on their livelihood ability. Journal of Nanjing Agricultural University (Social Sciences Edition) 4, 98-108.

Cai, J., Wang, T., Xia, X.L., Chen, Y.Z., Lv, H.Q., Li, N.. 2019. Analysis on the choice of livelihood strategy for peasant households renting out farmland: evidence from western poverty-stricken areas in China. 
Sustainability $11,1-13$.

Guo, X.B., Qiang, Z.Q. 2016. Chronic multidimensional poverty, inequality and causes of poverty. Economic Research Journal, 6, 143-156.

Hansen, B.E. 2000. Sample splitting and threshold estimation. Econometrica 68(3), 575-603.

Jin, S.Q., Jayne, T.S. 2013. Land rental markets in Kenya: implications for efficiency, equity, household income and poverty. Land Economics 89(2), 246-271.

Klasen, S., Felicitas, N.L.D. 2009. Poverty, inequality, and policy in Latin America. Cambridge, MA: MIT Press.

Li, G.K., Zhong, F.N. 2006. Farmland fragmentation, labor force utilization, and farmers' income-based on the empirical study of the less developed areas. Chinese Rural Economy 4, 42-48.

Li, L., Zhai, Z.W. 2018. How does farm land transfer influence family migration: theoretical analysis and evidence from three types of areas. South China Population 1, 1-9.

Liu, B.B., Lu, Q., Li, X.P. 2014. Social capital and household income in poverty area-test based on the threshold regression model. Journal of Agrotechnical Economics 11, 40-51.

Liu, J.S., Zhang, L. 2014. Analysis of the economic effect of the impact of land circulation on farmers' income. Journal of Northeast Agricultural University (Social Science Edition) 6, 20-24.

Mitra, S., Posarac, A., Vick, B. 2011. Disability and poverty in developing countries: a multidimensional study. World Development 41(1), 1-18.

Peng, D.Y., Wu, Y.J. 2009. An empirical test of the relation between concentration of farmland and increase of farmers' income. Chinese Rural Economy 4, 17-22.

Qian, Z.H., Wang, X.W. 2016. How does farmland transfer influence the income of farmer households?: An empirical analysis based on the survey data of farmer households in Jiangsu, Hubei, Guangxi, and Heilongjiang Provinces. Chinese Rural Economy 10, 39-50.

Ravallion, M. 2016. The economics of poverty: history, measurement, and policy. Oxford, UK: Oxford University Press.

Santos, M.E. 2014. Measuring multidimensional poverty in Latin America: previous experience and the way forward. Ophi Working Papers.

Shi, C.L., Luan, J., Zhu, J.F., Chen, Y.M. 2017. Land transaction and farmers' income - an analysis based Chinese eight Provinces survey data. Economic Review 5, 152-166.

Thuzar, M. 2010. Land in transition: reform and poverty in rural Vietnam. Journal of Southeast Asian Economies 25(3), 352-354.

Tian, C.H., Li, M.K. 2014. Land market development's impact on non-agricultural employment: based on the experience of Zhengjiang, Hubei and Shaanxi. Journal of Agrotechnical Economics 8, 11-24.

Tian, M., He, X.F. 2015. China's farmland fragmentation problem and its solution. Journal of Jiangxi University of Finance and Economics 2, 88-96.

Wang, J.H., Yang, C.Y., Xie, Y.M. 2019.The Policy Orientation and Evolution Logic of Rural Poverty Alleviation Ways__Based on the textual analysis of the Central "No. 1 Document." Reform 9, 138-148.

Wang, X.L., Alkire, S. 2009. Multidimensional poverty in China estimation and policy implications. Chinese Rural Economy 12, 4-10.

Whelan, C.T., Brian, N., Bertrand, M. 2014. GINI DP 40: Multidimensional poverty measurement in Europe: an 
application of the adjusted headcount approach. Journal of European Social Policy 24(2), 183-197.

Wietzke, F.B. 2020. Poverty, inequality, and fertility: the contribution of demographic change to global poverty reduction. Population and Development Review 46(1), 65-99.

Xia, Y.L., Kuang, Y.P. 2017. Multidimensional poverty reduction effects of farmland transfer: an analysis based on data collected from 1218 farm households in five provinces. Chinese Rural Economy 9, 44-61.

Xu, D.D., Yong, Z.L., Deng, X., Zhuang, L.1., Qing, C.. 2020. Rural-urban migration and its effect on land transfer in rural China. Land 9(3), 81.

Yang, C.H., Li, G.J. 2016. Empirical analysis on the relationship between agricultural productivity and scale of operation in the international perspective. Journal of Agrotechnical Economics 2, 4-13.

Yuan, H.N. 2009. The health and income of peasant-workers in cities: evidence from the survey of peasant-workers in Beijing. Management World 5, 56-66.

Zeng, F.S. 2015. Establishment the incentive and restraint mechanisms for food security through agricultural land rental. Issues in Agricultural Economy 1, 15-23.

Zhang, Q.H., Zhou, Q. 2014. On the dynamic multidimensional measurement and decomposition of China's poverty: 1989 2009. The Journal of Quantitative \& Technical Economics 6, 88-101.

Zhang, X.Y., Feng, H.X., Wang, X.L. 2016. The analysis of migrant women's multi-dimension poverty: based on the study of 451 housekeeping workers in Beijing. Economic Review 3, 95-107.

Zhang, Z., Yang, C.Y., Yuan, Q. 2017. Identification and mobility of the income-oriented multidimensional poverty - a study based on China family panel studies data. Economic Theory and Business Management $36(2), 98-112$.

Zhu, J.J., Hu, J.L., An, K., Huo, M.,. 2016. Analysis on the choice of livelihood strategies of peasant households who rent out the farmland and the influencing factors: based on CFPS data. Issues in Agricultural Economy 2, 49-58.

Zhu, M.B., Li, S. 2017. The key to precise poverty alleviation rests in the precise identification of impoverished populations: an analysis of the targeting effect of the rural subsistence allowance policy. Social Sciences in China 9, 90-112. 
Figures

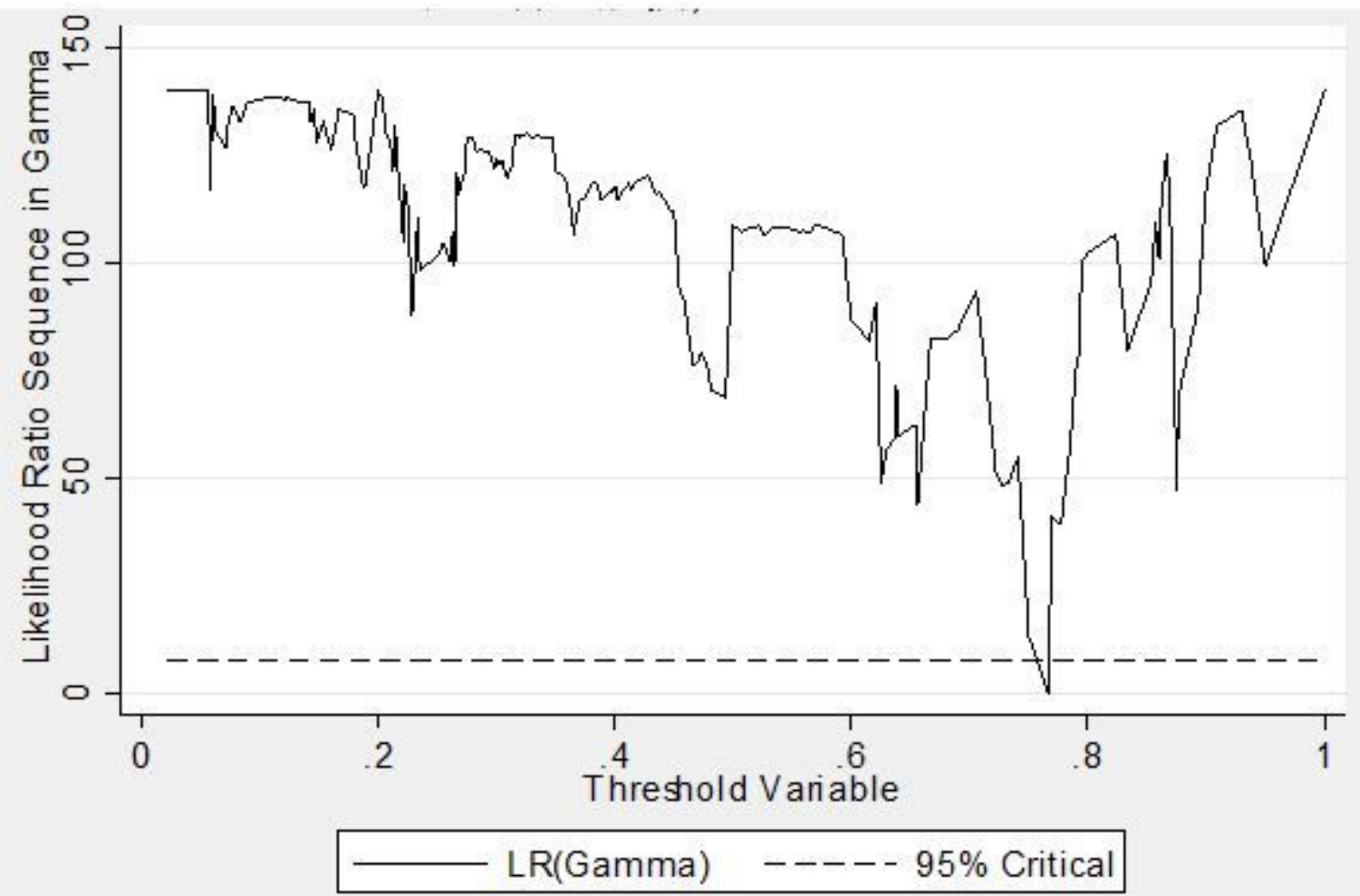

Figure 1

The first round: threshold variable Transfer-out scale. 